Fact Sheet

\title{
Lower-Cost Health Coverage Helps Pre-Medicare Older Adults in Wyoming
}

Olivia Dean and Jane Sung

The American Rescue Plan Act (ARPA) — signed into law in March 2021-increased the availability of affordable health coverage for Wyomingites ages 50 to 64 in years 2021 and 2022. The law expanded tax credits that help consumers pay premiums for health coverage purchased through Health Insurance Marketplaces, which are shopping and enrollment hubs created by the Affordable Care Act (ACA). Prior to this expansion of financial assistance, many older Wyomingites faced high premium costs that made health coverage unaffordable.

Many Wyomingites could be helped by the ARPA's expanded premium tax credits.

\section{0,239}

older adults in Wyoming purchase coverage on their own in the nongroup health insurance market.

\section{$36 \%$}

of older nongroup enrollees did not get financial help with their premium costs before the ARPA.

\section{$10 \%$}

of older nongroup enrollees delayed medical care due to cost before the ARPA.
While most adults ages 50 to 64 have health insurance through an employer or public program (such as Medicaid), 10,239 older Wyomingites purchased coverage on their own in the nongroup (individual) health insurance market in 2019. 7,237 enrolled in nongroup coverage through the state's Marketplace, while the rest purchased coverage off-Marketplace (through an agent/broker or directly from an insurer).

Under the ACA, federal subsidies that can be used to pay for premiums and out-of-pocket costs are available to people with certain incomes who enroll through the Marketplace. In 2019, 64\% of older nongroup enrollees in Wyoming received federal subsidies to help with premium costs, while $36 \%$ did not.

Prior to the ARPA, many older nongroup enrollees in Wyoming faced affordability challenges. In 2019, $15 \%$ of older nongroup enrollees in Wyoming reported issues paying medical bills, and $10 \%$ delayed medical care due to cost in the previous 12 months.

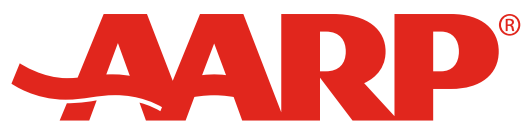




\section{$\$ 19,262$}

was the average unsubsidized premium for older

Marketplace enrollees before the ARPA.

\section{$\mathbf{8 1 \%}$}

of current Marketplace enrollees ages 55 to 64 are now eligible for a monthly premium of $\$ 50$ or less.*

\section{5,000}

older adults could potentially be helped by the ARPA.
Prior to the ARPA, people with incomes above $400 \%$ of the Federal Poverty Level were not eligible for any financial help and had to pay their full premiums, which could be up to three times higher for older enrollees than for younger adults.
Uninsured older adults could also significantly benefit from the new lower premiums under the ARPA. Over $60 \%$ of adults ages 55 to 64 who lack health insurance but are eligible for ACA coverage could now find a plan with a monthly premium of $\$ 50$ or less. Many are eligible for $\$ 0$ premium plans.

For 2021 and 2022, the ARPA expanded eligibility for federal premium subsidies to individuals with incomes above $400 \%$ of the Federal Poverty Level and increased the subsidies for those already eligible. Many of the 14,508 (or 13\% of) older Wyomingites who remain uninsured plus the 10,239 (or $10 \%$ of) older Wyomingites who are already enrolled in the nongroup market may be able to find more affordable coverage under the law.

The law could also help reduce racial and ethnic coverage gaps among adults ages 50 to 64 in Wyoming. Among this age group in 2019,22\% of Hispanic/ Latino adults were uninsured. In contrast, $13 \%$ of White adults in Wyoming were uninsured.

\footnotetext{
* National estimate. D. Keith Branham et al., "Access to Marketplace Plans with Low Premiums on the Federal Platform," Assistant Secretary for Planning and Evaluation, U.S. Department of Health and Human Services, Washington, DC, March 29, 2021, https://aspe.hhs.gov/sites/default/files/private/pdf/265291/low-premium-plans-issue-brief.pdf.
}

Note: 2019 data. Sources unless otherwise noted: KNG Health Reform Model 2020 (a microsimulation model developed by KNG Health Consulting LLC) and American Community Survey. 